\title{
MRI in intracavitary brachytherapy planning for cervical cancer malignancy, the pitfalls and complications
}

\author{
G Coniglio*, O Roche, C Maciel, A Sahdev
}

From International Cancer Imaging Society Meeting and 15th Annual Teaching Course (ICIS 2015) London, UK. 5-7 October 2015

\section{Learning objectives}

- Discuss the role and benefits of MRI in planning for brachytherapy treatment in cervical cancer.

- Discuss the key mechanisms of the applicator and the technical aspects of planning brachytherapy.

- Discuss the role of MRI imaging in recognising the features of appropriate applicator placement and common complications.

- Review key MRI features of radiation-related alterations in the pelvis post treatment and tumour response assessment.

\section{Contents}

- Anatomy of the female pelvic organs on MRI

- Key MRI imaging features of cervical cancer on MRI

- Review the staging of cervical cancer amenable to brachytherapy (FIGO)

- Advantages of brachytherapy versus external beam radiotherapy in treating cervical cancer.

- Technical aspects of applicator selection and positioning in brachytherapy.

- MRI features in assessment of appropriate placement of brachytherapy device, recognition of "organs at risk".

- Benefits of MRI versus more traditional imaging techniques CT and Radiographs, in brachytherapy planning.

- "Red flag" features of brachytherapy device misplacement in MRI.

- Features of tumour response and target organ assessment.

* Correspondence: giovanni.coniglio@bartshealth.nhs.uk

St Bartholomew's Hospital, W Smithfield, London, EC1A 7BE, UK
- Complications of brachytherapy including post radiation fibrosis.

\section{Conclusion}

- Analysis of MRI findings at the time of brachytherapy with the applicator is essential in the assessment of gross tumour volume, clinical target volumes and patho-anatomical structures.

- T2-weighted MR images minimise potential misinterpretation due to partial volume effects, which improves depiction of tumour in parametria, vaginal fornices, and cervix.

Published: 2 October 2015

doi:10.1186/1470-7330-15-S1-P36

Cite this article as: Coniglio et al:: MRI in intracavitary brachytherapy planning for cervical cancer malignancy, the pitfalls and complications. Cancer Imaging 2015 15(Suppl 1):P36.

Submit your next manuscript to BioMed Central and take full advantage of:

- Convenient online submission

- Thorough peer review

- No space constraints or color figure charges

- Immediate publication on acceptance

- Inclusion in PubMed, CAS, Scopus and Google Scholar

- Research which is freely available for redistribution 